\title{
Data Model
}

National Cancer Institute

\section{Source}

National Cancer Institute. Data Model. NCI Thesaurus. Code C142487.

Representation of standards recognized to represent information, including official expression and structure of elements as well as the relationship between elements, to retain the expected meaning. 